\title{
Survei Metrik Skala dan Kompleksitas Model Proses Bisnis
}

\author{
Ghani Mutaqin ${ }^{1, *}$, Yusuf Ansori², Naufal Tamam Santoso ${ }^{3}$, Muhammad Ainul Yaqin ${ }^{4}$ \\ Teknik Informatika, Universitas Islam Negeri Maulana Malik Ibrahim, Indonesia \\ 1' ghanimutaqin85@gmail.com; ${ }^{2} 18650041 @$ student.uin-malang.ac.id; ${ }^{3}$ naufaltamamsantoso@gmail.com, \\ ${ }^{4}$ yaqinov@ti.uin-malang.ac.id \\ * corresponding author
}

INFO ARTIKEL

Sejarah Artikel

Diterima: 18 Desember 2019

Direvisi: 13 Januari 2020

Diterbitkan: 30 April 2020

Kata Kunci

Model proses bisnis

Survei metrik skala

Kompleksitas

\section{ABSTRAK}

Model proses bisnis memiliki kompleksitas yang melekat yang jika tidak dikendalikan akan terus meningkat dengan waktu. Ini membuat model proses rawan kesalahan. Sulit untuk memahami dan memelihara. Agar model proses bisnis dapat terjaga dengan baik, maka diperlukan metrik yang dapat mengukur tingkat kompleksitas dari model proses bisnis tersebut. Sejumlah metrik yang ada dapat digunakan untuk mengukur kompleksitas dan karenanya dapat mengendalikan kompleksitas proses bisnis. Dalam penelitian ini, dilakukan survei terhadap metrik kompleksitas proses bisnis. Hasil dari survei ini di jabarkan dalam bentuk tabel untuk mempermudah dalam membandingkan setiap metrik dan penggunaannya pada model proses bisnis disetiap jurnal.

\section{PENDAHULUAN}

Proses bisnis dalam sebuah enterprise merupakan suatu bagian penting untuk mengukur seberapa baik enterprise tersebut [1]. Dalam sebuah organisasi yang bergerak dalam bidang bisnis, proses bisnis menjadi aset yang sangat menentukan gerak dan alur kerja dari organisasi tersebut. Proses bisnis tidak hanya membahas tentang bagaimana menghasilkan keuntungan yang besar, akan tetapi membahas secara mendalam dan terstruktur yang ditinjau dari segala aspek sehingga tercapai kapasitas produktif organisasi. Pemegang kendali proses bisnis juga mampu mengkoordinasikan, mengendalikan, dan menggunakan sumber daya sehingga organisasi dapat mencapai produktivitasnya [2]. Tujuan dari proses bisnis adalah untuk menghasilkan kepuasan pelanggan sehingga produksi akan berjalan terus-menerus. Kata proses merupakan suatu kata yang sulit untuk dijelaskan, karena kata tersebut merupakan kata yang abstrak dan tidak berwujud. Selain itu, proses juga tidak dapat diamati dan dikelola secara langsung [2]. Agar dapat memahami kata "proses" maka dilakukan sebuah pendekatan menggunakan metrik untuk mengukur tingkat kompleksitas dari kata tersebut. Metrik adalah sebuah mekanisme yang dapat digunakan untuk meningkatkan kualitas dari produk software dan juga untuk menentukan cara yang paling tepat untuk membantu praktisi dan peneliti [3]. Agar dapat mengetahui, dan memahami sebuah proses bisnis dengan menganalisa dari berbagai diagram, maka perlu memilih diagram yang paling kompleks, karena kompleksitas dapat meminimalisir tingkat kesalahan [2].

Dalam beberapa literatur, penulis menemukan beberapa metrik kompleksitas yang digunakan untuk mengukur kompleksitas dari sebuah model proses bisnis. Kemudian penulis tertarik untuk melakukan sebuah survei terhadap metrik yang sudah ada untuk mengetahui metode yang digunakan dan melakukan validasi dari metrik tersebut jika diperlukan. 


\section{METODE}

\section{Metode Model Proses Bisnis}

Proses bisnis adalah kumpulan proses untuk mengolah sesuatu sehingga dapat menghasilkan sesuatu yang baru. Model proses bisnis merupakan cara yang dapat mewakilkan sebuah proses bisnis menjadi model grafis yang sedang berkembang saat ini[4]. Model proses bisnis dapat diwakili dalam berbagai cara, yaitu Petri net, Business Process Model and Notation(BPMN), dan grafik[5].

\section{Kompleksitas Model Proses}

Kompleksitas dalam Polancic[4] menyebutkan kompleksitas merupakan ukuran sejauh mana suatu proses sulit untuk dianalisis, dipahami atau dijelaskan. Ini ditandai oleh jumlah dan kerumitan antarmuka aktivitas, transisi, cabang kondisional dan paralel, keberadaan loop, peran, kategori aktivitas, jenis struktur data, dan karakteristik proses lainnya. Dengan demikian, dalam memahami kompleksitas model membutuhkan investasi waktu untuk pemahaman secara mendalam.

\section{Pengukuran Kompleksitas dan Metrik}

Kebanyakan dari kita memahami bahwa melakukan proses pengukuran adalah menggunakan angka atau simbol-simbol, baik itu untuk mengukur sesuatu yang dapat diukur (nyata) atau dalam bentuk abstrak (tidak nyata) seperti contoh proses pengukuran model proses bisnis ini. Pengukuran dilakukan sedemikian rupa agar dapat menggambarkan sesuai dengan teori. Akan tetapi, proses pengukuran kompleksitas model proses bisa dilakukan dengan berbeda cara, yaitu melakukan pendekatan perspektif, disesuaikan landasan teori yang digunakan. Prosedur definisi metrik mencakup tiga langkah: (1) identifikasi entitas yang diukur (misalnya modul program dalam pemrograman atau model proses bisnis dalam kasus kami), (2) identifikasi atribut pengukuran yang diinginkan dari entitas (misalnya ukuran model proses) dan akhirnya (3) definisi metrik (misalnya jumlah kegiatan dalam model proses). Setelah metrik didefinisikan, kita dapat menilai kualitasnya[6].

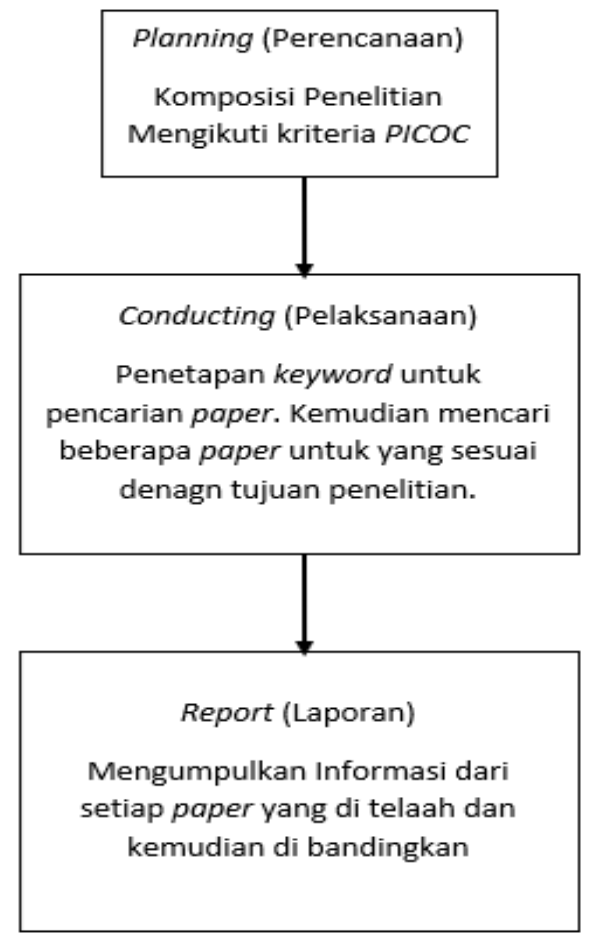

Gambar 1. Proses tahapan Systematic Literature Review 
Dalam melaksanakan penelitian ini penulis menggunakan metode penelitian Systematic Literature Review (SLR). Tinjauan pustaka sistematis adalah metode untuk mengidentifikasi dan menginterpretasi berbagai temuan pada sebuah topik penelitian untuk menjawab pertanyaan pada penelitian. Penulis menganggap metode SLR sesuai dalam tujuan penulis untuk menjawab pertanyaan-pertanyaan penelitian "Apakah metrik yang terdapat pada literatur dapat digunakan untuk mengukur kompleksitas diagram proses?". Dengan metode ini diharapkan akan mendapatkan gambaran baru tentang metrik dan kompleksitas model proses bisnis ini. Kemudian Penulis membuat desain alur penelitian yang sesuai dengan SLR agar penelitian dapat mencapai tujuan dan terstruktur. Alur dari penelitian yang penulis lakukan digambarkan dalam bentuk diagram blok pada Gambar 1.

\section{Planning (Perencanaan)}

Metode Systematic Literature Review SLR menggunakan komposisi PICOC dengan kriteria sebagai berikut:

- Population (populasi) : :Metrik kompleksitas model proses bisnis

- Intervention (intervensi) :Tinjauan metrik yang digunakan di setiap literatur

- Comparison (perbandingan):Hasil dan metode yang digunakan dalam literatur

- Outcome (hasil)

:Kesimpulan metrik yang diteliti

- Context (konteks)

:Metrik kompleksitas untuk model proses bisnis

\section{Conducting (Pelaksanaan)}

Pelaksanaan Systematic Literature Review SLR yang dilakukan adalah dengan menentukan keyword atau kata kunci untuk pencarian jurnal atau literatur yang sudah direncanakan yaitu "Apakah metrik yang terdapat pada literatur dapat digunakan untuk mengukur kompleksitas diagram proses?". Keyword atau kata kunci dalam penelitian ini yaitu:

("survei" atau "Survei" atau "kompleksitas" atau "complexity" atau "mengukur" atau "measuring")

dan

("metrik" atau "metric" atau "skala" atau "scale" atau "scalability")

dan

("model proses bisnis" atau "business process model")

kemudian membatasi pencarian beberapa literatur selama 15 tahun terakhir dan memiliki judul atau isi yang relevan terhadap penelitian di beberapa perpustakaan digital seperti: IEEExplore, Springerlink, Google Scholar, Researchgate, dan Explore It!.

\section{Reporting (Pelaporan)}

Setelah melakukan pencarian sumber atau literatur yang sesuai dengan kriteria untuk penelitian ini. hasil pencarian yang kami temukan adalah 6 paper yang sesuai dengan kriteria untuk penelitian ini.

\section{HASIL DAN PEMBAHASAN}

Bagian berikut ini adalah beberapa metrik yang telah dikelompokkan oleh penulis. Identifikasi metrik didasarkan pada kasus apakah mereka termasuk dalam ruang lingkup kompleksitas proses bisnis. Dalam studi literatur ini, penulis tidak menunjukkan ada dukungan alat atau tidak. Juga, di mana studi empiris dicatat, mereka biasanya mengambil bentuk eksperimen. Untuk mengetahui perbedaan dari setiap literatur maka dibuatlah Tabel 1 hasil perbandingan literatur: 
Tabel 1. Hasil Perbandingan jurnal atau literatur

\begin{tabular}{|c|c|c|c|c|}
\hline Tahun & Penulis & Judul & Metode & Hasil \\
\hline 2010 & $\begin{array}{l}\text { G. M. } \\
\text { Muketha, A. A. } \\
\text { A. Ghani, M. } \\
\text { H. Selamat, } \\
\text { and R. Atan }\end{array}$ & $\begin{array}{l}\text { Survei Complexity of } \\
\text { Business Complexity } \\
\text { Metrics[2] }\end{array}$ & $\begin{array}{l}\text { 1. Identifikasi } \\
\text { Pengukuran Satuan } \\
\text { 2. Definisi Metrik } \\
\text { berdasar praktek dan } \\
\text { teori }\end{array}$ & $\begin{array}{l}\text { Hanya beberapa metrik yang } \\
\text { tervalidasi baik secara } \\
\text { empiris maupun teoritis }\end{array}$ \\
\hline 2015 & Burak, Dariusz & $\begin{array}{l}\text { Measuring Complexity } \\
\text { of Business Process } \\
\text { Models Integrated with } \\
\text { Rules[7] }\end{array}$ & $\begin{array}{l}\text { Mempertimbangkan metrik } \\
\text { baru yang cocok untuk } \\
\text { mengukur model terintegrasi } \\
\text { dan menyajikan evaluasi } \\
\text { singkat berdasarkan kasus yang } \\
\text { dipilih dari ukuran yang } \\
\text { berbeda. }\end{array}$ & $\begin{array}{l}\text {-Mempertimbangkan matrik } \\
\text { baru yang cocok untuk } \\
\text { mengukur integrasi model } \\
\text { dan menyajikan evaluasi } \\
\text { berdasarkan kasus dari } \\
\text { ukuran yang berbeda }\end{array}$ \\
\hline 2017 & $\begin{array}{l}\text { Yaqin, } \\
\text { Muhammad } \\
\text { Ainul } \\
\text { Sarno, } \\
\text { Riyanarto } \\
\text { Fauzan, Abd } \\
\text { Charis }\end{array}$ & $\begin{array}{l}\text { Scalability } \\
\text { Measurement of } \\
\text { Business Process } \\
\text { Model } \\
\text { Using Business } \\
\text { Processes Similarity } \\
\text { and Complexity[1] }\end{array}$ & $\begin{array}{l}\text { 1. Pemodelan proses } \\
\text { bisnis dengan } \text { net } \\
\text { entry } \\
\text { 2. menghitung kesamaan } \\
\text { alur kerja } \\
\text { 3. } \begin{array}{l}\text { menghitung alur kerja } \\
\text { skalabilitas }\end{array} \\
\text { 4. Analisa skalabilitas } \\
\text { secara ekstrim kasus }\end{array}$ & $\begin{array}{l}\text { 1. Nilai skalabilitas } \\
\text { dipengaruhi oleh } \\
\text { indeks kesamaan, } \\
\text { jumlah elemen } \\
\text { dalam model proses } \\
\text { bisnis, dan } \\
\text { kompleksitas } \\
\text { kontrol aliran } \\
\text { 2. Indeks kesamaan } \\
\text { pada pengukuran } \\
\text { skalabilitas adalah } \\
\text { digunakan untuk } \\
\text { memastikan bisnis } \\
\text { yang dibandingkan } \\
\text { model proses } \\
\text { memiliki } \\
\text { persimpangan } \\
\text { Nilai skala sangat } \\
\text { penting pada } \\
\text { mengukur } \\
\text { skalabilitas. } \\
\text { Formulasi } \\
\text { perhitungan metrik } \\
\text { skalabilitas tidak } \\
\text { dapat digunakan } \\
\text { pada kasus saat } \\
\text { bisnis model proses } \\
\text { memiliki struktur } \\
\text { yang sama tetapi } \\
\text { memiliki perilaku } \\
\text { yang sama sekali }\end{array}$ \\
\hline
\end{tabular}




\begin{tabular}{|c|c|c|c|c|}
\hline & & & & $\begin{array}{l}\text { berbeda atau } \\
\text { sebaliknya. }\end{array}$ \\
\hline 2019 & $\begin{array}{l}\text { Muhammad } \\
\text { Ainul Yaqin, } \\
\text { Dian Permana } \\
\text { Putra, Faizal } \\
\text { Armas Fata, } \\
\text { Lailatul } \\
\text { Maghfiroh }\end{array}$ & $\begin{array}{l}\text { Pengukuran Metrik } \\
\text { Kompleksitas Model } \\
\text { Proses Bisnis Pondok } \\
\text { Pesantren [6] }\end{array}$ & 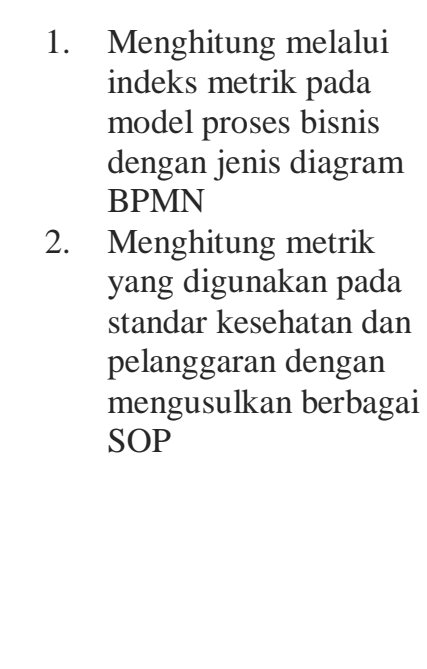 & $\begin{array}{ll}\text { 1. } & 22 \text { metrik } \\
\text { digunakan dalam } \\
\text { pembuatan dan } \\
\text { SOP dan } \\
\text { penghitungan pada } \\
\text { model proses bisnis } \\
\text { dengan diagram } \\
\text { BPMN. } \\
\text { Mengukur indeks } \\
\text { metrik dengan } \\
\text { memodelkan } \\
\text { terlebih dahulu } \\
\text { proses bisnis nya, } \\
\text { kompleksitas } \\
\text { metrik dalam paper } \\
\text { ini dapat dihitung. }\end{array}$ \\
\hline 2006 & $\begin{array}{l}\text { Volker Gruhn, } \\
\text { Ralf Laue }\end{array}$ & $\begin{array}{l}\text { Complexity Metrics } \\
\text { for Business Process } \\
\text { Models[8] }\end{array}$ & $\begin{array}{l}\text { Menggunakan hasil } \\
\text { penelitian kompleksitas } \\
\text { software untuk digunakan } \\
\text { sebagai bahan analisa } \\
\text { kompleksitas model proses } \\
\text { bisnis }\end{array}$ & $\begin{array}{l}\text { Metrik yang digunakan } \\
\text { dalam paper ini dapat } \\
\text { juga dipakai untuk } \\
\text { kompleksitas model } \\
\text { proses bisnis, setiap } \\
\text { metrik mengukur salah } \\
\text { satu aspek dari } \\
\text { kompleksitasnya yang } \\
\text { kemudian digabungkan } \\
\text { menjadi hasil yang lebih } \\
\text { akurat. dalam paper ini } \\
\text { tidak dapat menemukan } \\
\text { satu metrik yang dapat } \\
\text { mengukur seluruh aspek } \\
\text { dari kompleksitas model } \\
\text { proses bisnis } \\
\text { dikarenakan banyak } \\
\text { faktor yang berkontribusi } \\
\text { dalam BPM } \\
\text { kompleksitas }\end{array}$ \\
\hline 2018 & Mike A. Marin & $\begin{array}{l}\text { Exploring Complexity } \\
\text { Metrics for Artifact- } \\
\text { Centric Business } \\
\text { Process Models [9] }\end{array}$ & $\begin{array}{l}\text { merujuk pada beberapa } \\
\text { metrik dari peneliti } \\
\text { sebelumnya dengan } \\
\text { menggunakan metode } \\
\text { survei online dengan } \\
\text { mengadopsi pendekatan }\end{array}$ & 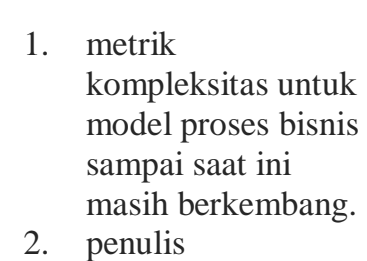 \\
\hline
\end{tabular}




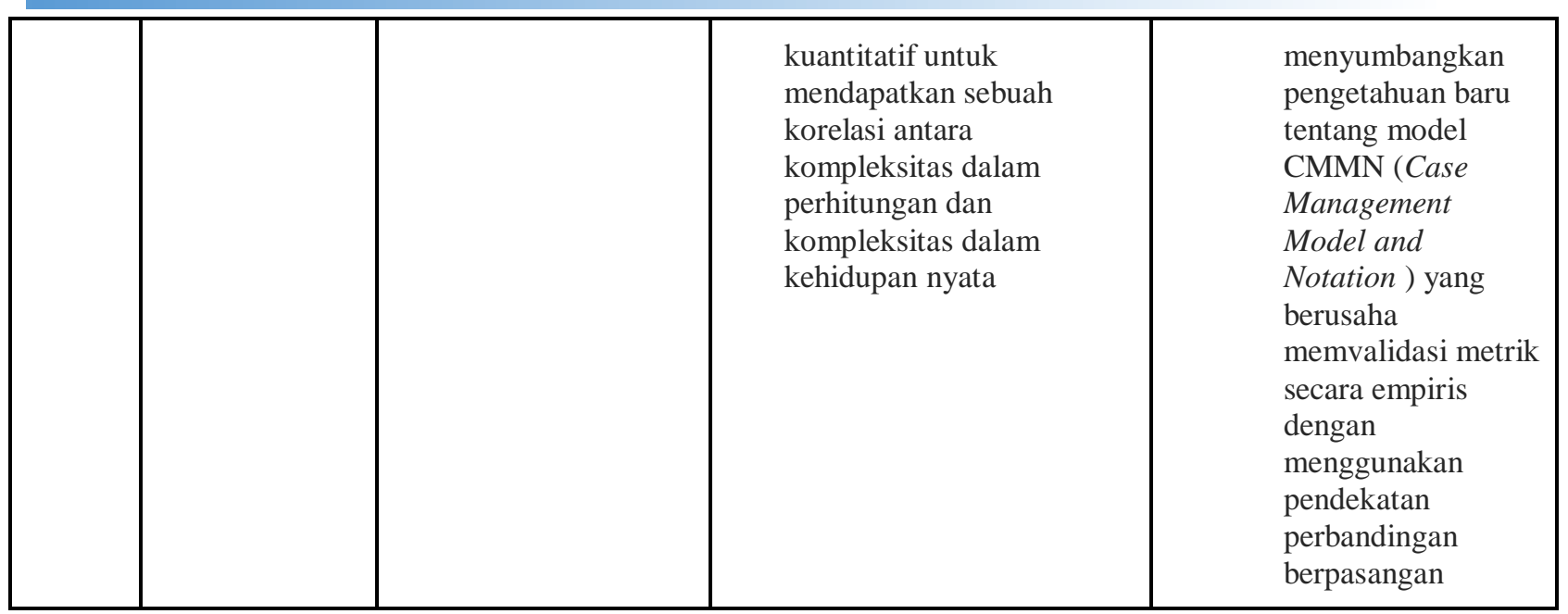

\section{KESIMPULAN}

Hanya sejumlah kecil dari metrik yang telah diusulkan yang tervalidasi baik secara teori maupun praktek. Selain itu belum ada alat yang mendukung untuk membuktikan secara valid tentang metrik pada model proses bisnis yang sangat kompleks. ketika berbagai eksperimen menunjukan hasil yang beragam. apabila telah dapat dibuktikan secara teoritis maupun empiris, maka tujuan untuk mengukur metrik yang valid pada proses model bisnis akan dengan mudah tercapai.

\section{REFERENSI}

[1] M. A. Yaqin, R. Sarno, and A. C. Fauzan, "Scalability measurement of business process model using business processes similarity and complexity," Int. Conf. Electr. Eng. Comput. Sci. Informatics, vol. 4, no. September, pp. 306-312, 2017, doi: 10.11591/eecsi.4.1033.

[2] G. M. Muketha, A. A. A. Ghani, M. H. Selamat, and R. Atan, "A Survei of business process complexity metrics," Inf. Technol. J., vol. 9, no. 7, pp. 1336-1344, 2010, doi: 10.3923/itj.2010.1336.1344.

[3] L. Sánchez-González, F. Ruiz, F. García, and J. Cardoso, "Towards thresholds of control flow complexity measures for BPMN models,” Proc. ACM Symp. Appl. Comput., no. January, pp. 14451450, 2011, doi: 10.1145/1982185.1982496.

[4] G. Polančič and B. Cegnar, "Complexity metrics for process models - A systematic literature review," Comput. Stand. Interfaces, vol. 51, pp. 104-117, 2017, doi: 10.1016/j.csi.2016.12.003.

[5] W. Kbaier and S. A. Ghannouchi, "ScienceDirect ScienceDirect Determining The Threshold Values Of Quality Metrics In Determining The Threshold Values Of Quality Metrics In BPMN Process Models Using Data Mining Techniques BPMN Process Models Using Data Mining b Techniques," Procedia Comput. Sci., vol. 164, pp. 113-119, 2019, doi: 10.1016/j.procs.2019.12.161.

[6] M. A. Yaqin, D. P. Putra, and F. A. Fata, "Pengukuran Metrik Kompleksitas Model Proses Bisnis Pondok Pesantren," Explor. IT J. Keilmuan dan Apl. Tek. Inform., vol. 11, no. 2, pp. 1-10, 2019, doi: 10.35891/explorit.v11i2.1793.

[7] D. Burak, "Parallelization of a Block Cipher Based Description of the Block Cipher Based on Chaotic," Int. Conf. Artif. Intell. Soft Comput. ICAISC 2015 Artif. Intell. Soft Comput., pp. 191-201, 2015, doi: 10.1007/978-3-319-19369-4.

[8] K. Kluza, G. J. Nalepa, and J. Lisiecki, "Square complexity metrics for business process models," $A d v$. Intell. Syst. Comput., vol. 257, no. June, pp. 89-107, 2014, doi: 10.1007/978-3-319-03677-9_6.

[9] M. A. Marin, "Exploring complexity metrics for artifact-centric business process models," CEUR Workshop Proc., vol. 2196, pp. 1-5, 2018. 